\title{
Husserl e a metafísica da subjetividade: uma crítica heideggeriana a partir da noção de superação
}

\section{Husserl and the metaphysics of subjectivity: a Heideggerian critique from the notion of overcoming}

DOI: $10.12957 /$ ek.2018.36557

\author{
Dr. Gustavo Augusto da Silva Ferreira \\ professorgustavoferreira@hotmail.com.br \\ Universidade Federal do Ceará
}

A crítica de Heidegger àquilo que ele chama de metafísica da subjetividade tem seu momento mais elevado quando o mesmo volta os olhos para a filosofia fenomenológica de Husserl. Não podendo abrir mão da crítica da filosofia husserliana para a realização de seu projeto de crítica da metafísica da subjetividade enquanto continuação do esquecimento do ser inerente à história do pensamento ocidental, Heidegger propõe a superação da fenomenologia transcendental de Husserl pela fenomenologia hermenêutica. Tal superação constitui o cerne do projeto heideggeriano no todo de sua crítica da metafísica da subjetividade, esta última tendo seu auge em Husserl e, consequentemente, o auge de tal superação sendo a leitura crítica da filosofia de Husserl, no que tange à metafísica da subjetividade.

\section{PALAVRAS-CHAVE \\ Heidegger. Metafísica da Subjetividade. \\ Husserl. Fenomenologia. Superação}

Heidegger's critique of what he calls the metaphysics of subjectivity has its highest moment when he turns his eyes to Husserl's phenomenological philosophy. Heidegger proposes an overcoming of Husserl's transcendental phenomenology by hermeneutic phenomenology. He abandon the criticism of Husserlian philosophy for the realization of his critique of the metaphysics of subjectivity as a continuation of the forgetfulness inherent in the history of Western thought. Such overcoming constitutes the heart of the Heideggerian project in the whole of his critique of the metaphysics of subjectivity, the latter having its pinnacle in Husserl and, consequently, the peak of such overcoming being the critical reading of Husserl's philosophy, as regards the metaphysics of subjectivity. 


\section{Considerações introdutórias}

Segundo Martin Heidegger, Edmund Husserl é o continuador da metafísica da subjetividade, representando, por assim dizer, o seu auge, ${ }^{1}$ o herdeiro mais legítimo de uma tradição ${ }^{2}$ que se originou em Descartes e percorreu toda a modernidade, rumo ao século XX. Mas por quê? O que há em Husserl que torna possível a concepção heideggeriana da continuação de tal metafísica? Além da concepção de sujeito, ou da dicotômica e problemática manutenção da relação sujeito-objeto, Husserl, tal como o Kant da primeira Crítica, está interessado especialmente na problemática do conhecimento, ou melhor, nas condições de possibilidade do mesmo. Se as considerações acerca de tais condições de possibilidade tornou possível, em Descartes, a teoria do "eu penso", e, em Kant, o transcendental inerente ao seu criticismo, estas, em Husserl, darão o mote para o surgimento do que o mesmo designará como fenomenologia transcendental. O próprio Husserl, em A filosofia como ciência de rigor, enfatiza que a problemática do conhecimento é, enquanto tal, o problema fundamental da filosofia, o que a caracteriza em seu caráter mais profundo, particular e original.

Em um de seus principais escritos, intitulado Ideias para uma fenomenologia pura e para uma filosofia fenomenológica, esta já sendo uma obra de maturidade do autor, o mesmo declina, para nós, os princípios fundamentais de sua filosofia e concepção de conhecimento, ou melhor, a sua fenomenologia transcendental, não discordando de modo algum da ideia original vigente na obra de juventude supracitada.

Segundo Jesús Vásquez Torrez,

\footnotetext{
1 Apesar de Sigmund Freud (Cf.: HEIDEGGER, Martin. Seminários de Zollikon. Editora Vozes e Editora Universitária São Francisco. Ed. $2^{\mathrm{a}}$. Trad. De Gabriella Arnhold e Maria Fátima de Almeida Prado. São Paulo. 2009), também, de certo modo, dar continuidade ao viés da metafísica da subjetividade da tradição, segundo Heidegger, Husserl é, indubitavelmente, o nome de maior destaque de tal tradição (na época de Heidegger).

2 A noção de tradição é tão cara quanto complexa, no que é relativo à aparição da mesma no pensamento heideggeriano. Não nos aprofundaremos neste conceito e sua significação para Heidegger para não incorrermos no risco de nos desviar de nosso objeto central. Todavia, peço que o leitor não perca de vista a riqueza conceitual deste termo tão caro a Heidegger, o qual deverá aparecer em diversos momentos tanto na obra heideggeriana, quanto, às vezes, aqui. De antemão, basta apenas observarmos que a tradição significa aquilo que resguarda o cerne da filosofia como história do esquecimento do ser, a tradição é, para Heidegger, a condutora onto-teo-lógica fundamental, aquela que transformou a história do pensamento ocidental, ou, até mesmo, da filosofia, em história do ente, ou do ente em detrimento do ser, ou ainda e principalmente, em história da filosofia como metafísica, história do pensamento ocidental como esquecimento do ser.
} 
Husserl e a metafísica da subjetividade: uma crítica heideggeriana a partir da noção de superação

(...) o modo de pensar de Heidegger enquanto realização do "passo de volta", de "repetição" e "desconstrução" da tradição metafísica é dado a partir da forte influência recebida da fenomenologia husserliana, incluindo-a nessa tarefa desconstrutiva, e de sua peculiar leitura de Kant. Nesse sentido, parece legítimo interpretar globalmente o pensamento de Heidegger como uma radicalização fenomenológica da fenomenologia de Husserl (...). (TORRES, 2000, p. 72)

O que Torrez chama aqui de "passo de volta" pode ser entendido neste escrito, assim como o que Ernildo Stein chama de "desleitura"3, como a intenção por detrás do que Heidegger afirmara com a destruição, no $\S 6$ de Ser e tempo.

Poderíamos até mesmo, junto à destruição, falar também de desconstrução ou, ainda, de desmonte da metafísica tradicional. Pois, se, no $§ 6$ de Ser e tempo, Heidegger fala de destruição, nas obras seguintes essa destruição aparece horas na forma de desmonte, horas na forma de desconstrução. Heidegger apresenta, em quase toda a obra posterior a Ser e tempo, a desconstrução que o mesmo propusera em Ser e tempo e só brevemente, lá, a apontara. Heidegger fala da tarefa de uma destruição da história da ontologia. Como afirma Gadamer, ${ }^{4}$ o pôr a mostra, como atividade antecipadora, era o sentido do que o jovem Heidegger denominara como destruição, no caso, em Ser e tempo. Ser e tempo antecipara, através da destruição, como atividade antecipadora, o que surgiria, em breve, como, também e complementarmente, mas não de forma explicitamente conceitual, desconstrução e desmonte da tradição. Destruição, aqui, aponta para a necessidade do fim, como quando, em Técnica e arte, Heidegger, ao falar da destruição da arte, fala do fim da mesma, no sentido de esta estar a ser absorvida pela técnica, pelo dispositivo, Gestell, como referencia em A questão da técnica ${ }^{5}$. Destruição parece aparecer, para além de atividade, também como tarefa, tal como traz o título do $\S 6$ de Ser e tempo: A tarefa de uma destruição da história da ontologia. Ao falar em destruir lembremos que não se trata de abandonar, mas - e aqui nos remetemos para outra noção importante — superar.

3 Cf.: STEIN, Ernildo. Às voltas da metafísica com a fenomenologia. Editora Unijuí, 2014. Ijuí, Rio Grande do Sul - RS. Pp.19-23.

4 Cf.: GADAMER, H.G. - Geleitwort. In: Biemel, W. e Hermann, F-W (editores) - Kunst und Technik - Frankfurt a. M., 1989, p. XVI.

5 Cf.: STEIN, Ernildo. Destruição da metafisica ou crise da metafisica e crise da estética (simetria e reversibilidade). Presente em: Revista do Programa de Pós Graduação em Letras da UFSM. No 54. Junho de 2017. Pp. 64-72. 
Neste sentido, a destruição, configurando a necessidade de desconstrução e atividade de desmonte, aparece, quase inevitavelmente, como superação. Destruir não significa abandonar, como quem joga uma pedra em uma vidraça e depois se retira do local do ocorrido. Significa, isto sim, superar. "Superação", Verwindung, carrega, após Ser e tempo, o sentido de destruição, alocando a este desconstrução e desmonte: desconstrução porque é o que é feito no decorrer da obra heideggeriana após Ser e tempo, cumprindo a tarefa posta no §6 de Ser e tempo. Desmonte porque a desconstrução não é feita de uma só vez, em uma só obra, e por completo, mas por partes, em várias obras, momentos, etapas, portanto a desconstrução assume, também, a forma de desmonte, caracterizando assim a proposta de destruição.

Mas esta destruição, como acabamos de mencionar, logo se converterá em superação, como é usado em um significativo texto intitulado $A$ superação $d a$ metafísica. Heidegger não mais mencionará, a partir da década de 1930, a destruição, mesmo já realizando, nos textos posteriores a Ser e tempo, a destruição enquanto desconstrução e desmonte da tradição, em variados textos e momentos. Heidegger usará, a partir de então, superação, onde mencionará em textos como Sendas perdidas, Identidade e diferença (na primeira parte) e no já citado A superação da metafísica. ${ }^{6} \mathrm{O} \S 6$ de Ser e tempo dá a senha, apresenta a intuição e inicia o movimento: daí a sua considerável importância.

Não obstante, e também não coincidentemente, no parágrafo seguinte, Heidegger esboça a sua concepção de fenomenologia ${ }^{7}$, a qual já anuncia, por assim dizer, o rompimento com aquele que ele próprio designara como o seu "Honorável Mestre", a saber, Edmund Husserl. O "anúncio" do rompimento com o mestre anunciara também o irromper da "fenomenologia hermenêutica" heideggeriana, que dá primazia ao âmbito da "compreensão" em detrimento da relação sujeito-objeto. Apesar da citada "necessidade ou tarefa de uma destruição da tradição", da metafísica tradicional, vale lembrar que, para Heidegger, “(...) a superação da metafísica não é o fim da metafísica”, como o mesmo afirma logo nos primeiros momentos de Kant e o problema da metafísica. ${ }^{8} \mathrm{Se}$ assim o é, o rompimento que se dá aqui entre Heidegger e Husserl se dá, primordialmente, a partir da problemática do conhecimento, a partir da instância

6 Uma leitura interessante, para melhor compreensão - no caso, uma compreensão crítica - da noção de superação em Heidegger, é a de Vattimo, presente em VATTIMO, G.. O fim da modernidade: Niilismo e hermenêutica na cultura pós-moderna. Martins Fontes: São Paulo, 2002.

7 Cf.: $§ 7$ de Ser e tempo e HEIDEGGER, Martin. Meu caminho para a fenomenologia.

8 C.f.: Capítulo I de: HEIDEGGER, Martin. Kant und das Problem der Metaphysik. Frankfurt am Main: Vittorio Klostermann, 1991. 
de distinção fenomenológica, que torna possível, de um lado, a fenomenologia transcendental e, de outro, a fenomenologia hermenêutica.

As cartas trocadas entre Heidegger e Husserl acerca do verbete fenomenologia, escrito pelos dois para a Enciclopédia Britânica ${ }^{9}$, destaca bem essa separação a partir de tal problema ${ }^{10}$, principalmente a partir da leitura da famosa e polêmica carta ${ }^{11}$ de Heidegger a Husserl acerca de tal verbete. Desta sorte, é necessário fazer aqui uma breve exposição da fenomenologia husserliana, para, em seguida, declinar a justificação fundamental acerca do fato de a mesma constituir uma continuação da metafísica da subjetividade, e como Heidegger parece enxergar isso. Pois, se esta assim o é (metafísica da subjetividade), ela está automaticamente inserida no projeto heideggeriano de destruição da tradição metafísica, da ontologia tradicional, mas vale lembrar que, em Heidegger, como citamos acima, a destruição ou desconstrução não é o fim da metafísica, mas a significação do estatuto de sua superação. ${ }^{12}$

\section{Husserl: fenomenologia e crítica do conhecimento}

A problemática epistemológica constitui um dos principais pilares da tradição filosófica, a qual serve-nos de fio condutor para uma introdução à questão da fenomenologia. A interrogação básica que se mostra no desenrolar do processo é: como os objetos ou o mundo se constituem para a consciência como um todo? Ou

9 Cf.: HEIDEGGER, Martin. Versuch einer zweiten Bearbeintung [Encyclopaedia Britannica]. Presente em> HUSSERL, Edmund. Phänomenologische Psychologie (Husserliana IX). Nijhoff, La Haye, 1962. Pp. 256-263.

10 Para maior aprofundamento do momento central do rompimento de Heidegger com Husserl a partir da problemática do conhecimento, remeto o leitor a STEIN, Ernildo. Mundo e subjetividade: o núcleo da diferença entre Husserl e Heidegger. Presente em: Às voltas com a questão do sujeito: posições e perspectivas. Editora UNIJAI e Editora UNIOESTE. Org. de César Augusto Battisti. 2010.

11 Cf.: HEIDEGGER, Martin. Brief an Edmund Husserl [Encyclopaedia Britannica]. 22.10.1927. Presente em: HUSSERL, Edmund. Phänomenologische Psychologie (Husserliana IX). Nijhoff, La Haye, 1962. Pp. 600-603.

12 Heidegger usa, raras vezes, também a expressão Überwindung, no que estamos a chamar aqui de superação. Mas no início de $A$ superação da metafísica, ele explica que a noção apropriada, em relação à sua proposta frente o que esta sendo historicamente apresentado, é Verwindung. Heidegger, no texto intitulado de $A$ superação (grifo nosso) da metafísica, use Verwindung, pois, em Heidegger, paradoxalmente, parece haver a combinação de Überwidung e Verwindung no sentido de que Überwidung seria uma leitura corretiva e desenraizadora da tradição metafísica, enquanto Verwindung seria uma leitura inovadora e instauradora, a leitura para o que ficara oculto na história, o esquecimento do ser. Neste sentido, por uma lado a contação original da história, por outro, a contação originária, a história em seu equívoco mais a combinação da singularidade e necessidade da superação de tal equívoco. 
melhor: existe um mundo propriamente dito, externo à consciência, em si mesmo, ou a consciência formula a sua própria temática e, por conseguinte, formula o seu mundo? Tal questão foi por muito tempo discutida por grandes filósofos como René Descartes, David Hume, Immanuel Kant e outros. Porém, o esclarecimento da questão, no que diz respeito ao naturalismo e à propriedade da consciência enquanto modificadora da realidade ou modificada por esta no que tange ao que é pela própria consciência produzido, mesmo com todo o esforço da tradição, continuara em aberto para Husserl. O seu esforço gira em torno da análise de tais questões, todavia, com os mesmos operadores conceituais da tradição.

Para Husserl, assim como para alguns outros epistemólogos, os objetos se constituem graças aos atos da consciência, a mesma não precisando da realidade para existir e, não obstante, a realidade, ao contrario, dependendo da consciência de forma irrecusável. A realidade, não enquanto realidade em si, mas como realidade enquanto objeto, como conhecimento ou conhecida pela consciência, depende da consciência. Tudo, neste sentido, seguindo a linha do idealismo - mas não um idealismo absoluto, e sim um idealismo transcendental - se revela na consciência como objeto constituído por atos constituintes. Numa postura transcendental, a noção de realidade somente aparece como realidade para a consciência. O filósofo não exclui a questão do subjugo da consciência com relação à realidade, nem a sua relação com o mundo de forma meramente empírica, ao contrário, para Husserl, a fenomenologia é apenas um dos lados de nosso universo intelectual, que não suprime o outro, aquele que se desdobra na direção natural. Todavia, o privilégio e primazia da questão se dá na consciência, não na realidade do ponto de vista naturalista, empírico etc.

$\mathrm{Na}$ orientação fenomenológica, ao contrário da tão comumente e usual orientação natural, o interesse não se dirige às coisas, mas sim aos fenômenos, quer dizer, aos múltiplos modos subjetivos de doação graças aos quais temos, por assim dizer, consciência dos objetos. É apenas quando nos situamos nesta orientação que operamos a redução fenomenológica, quer dizer, a transição da investigação das coisas para os seus fenômenos. As verdades fenomenológicas não são opiniões sobre o mundo existente, a redução será por definição a proibição de se fazer qualquer relato sobre o mundo puro e simples. Todavia, como dissemos acima, os "operadores" ${ }^{13}$ conceituais da tradição da metafísica da

13 Escolhemos aqui o termo "operadores" para nos referir àqueles conceitos que Heidegger não somente evita se utilizar como, também, critica, os quais são de importância demasiada na metafísica da subjetividade, tais como sujeito, objeto, consciência etc. Mas o leitor, pedimos, deve sentir-se à vontade para, no lugar de "operadores", se utilizar de "conceitos", noções" etc., pois cremos que tal substituição por parte do leitor não diminuiria ou transgrediria o sentido do que estamos a afirmar. 
subjetividade (Heidegger), ou da tradição filosófico-epistemológica (Husserl), permanecem, como o leitor já deve ter notado: sujeito, objeto, consciência, etc.

A fenomenologia aqui se apresenta como método: método de conhecimento descritivo que se encarrega de fornecer as "verdades" que a ciência nos omite e que nos aparecem em contraposição às ciências, para uma melhor compreensão da realidade, compreensão menos equívoca e mais abrangente. Compreender a fenomenologia husserliana, nesta perspectiva, seria entender as condições de possibilidade de todo entendimento. Para Husserl, filosofia é análise rigorosa das possibilidades do conhecimento. Porém, na fenomenologia husserliana, o objeto é ele mesmo subjetivo; o nome do objeto (ao contrário do que nos diziam uma parcela dos filósofos medievais) não designa a sua realidade, essência ou existência propriamente dita, nem no sentido de correspondência com a ideia que se tem dele (o que seria uma ilusão partirmos deste pressuposto), nem mesmo com o pressuposto aparentemente lógico que o define como concordância universal do entendimento acerca de sua utilidade ou funcionabilidade (onde, crer nisso, seria uma impressão ingênua de nossa parte).

Partindo das condições de possibilidade do conhecimento, podemos afirmar com nítida certeza que o território da pesquisa de Husserl será a intencionalidade, conceito que, segundo Heidegger, é o fator diferencial da filosofia de Husserl em relação às demais metafísicas da subjetividade. Todavia, para Heidegger, a noção de intencionalidade, não obstante, já estaria presente na filosofia do mestre de Husserl, Brentano, mas em Husserl toma nova e mais completa roupagem, sob o viés fenomenológico.

Sobre a fenomenologia, diz Husserl inicialmente:

(...) ela se denomina como uma ciência de "fenômenos". Também outras ciências há muito conhecidas se voltam para fenômenos. É assim que ouvimos a psicologia ser designada como uma ciência das "manifestações" ou fenômenos físicos; da mesma maneira, na história, por vezes se fala de fenômenos históricos e, nas ciências que estudam as civilizações, de fenômenos das civilizações; e assim semelhantemente em todas as ciências de realidades. (HUSSERL, 2006, P. 25) ${ }^{14}$

14 Com a presente afirmação fica claro que existem inúmeras outras disciplinas científicas que se denominam fenomenológicas, porém, a fenomenologia no âmbito da presente investigação, se mostra como uma filosofia de rigor. 
A fenomenologia, em Husserl, é fundamentalmente um método, estrutura-se como procedimento investigativo, rumo aos fenômenos. Importantes textos husserlianos declinam tal concepção, mas a base e ponto de apoio central e principal do desenvolvimento de tal ideia é a obra Ideias para uma fenomenologia pura e para uma filosofia fenomenológica, tendo como apoio as Investigações lógicas, as Meditações Cartesianas e a Filosofia como ciência de rigor.

A fenomenologia, que é o ponto central da exposição husserliana, é uma posição única, inovadora e radical perante as demais ciências. A mesma se pretende uma ciência dos fenômenos opondo-se ao que Husserl entendia como naturalismo prático e tradicional, a que o pensamento há muito se apegara. Essa mesma fenomenologia fez sua primeira aparição na obra Investigações Lógicas, onde os seus fundamentos mais primários são totalmente distintos da psicologia no sentido husserliano. Logo, a fenomenologia de forma alguma pode ser considerada psicologia ou uma ciência psicológica, ao contrário. Segundo Husserl, o que impede a inclusão da fenomenologia no âmbito da psicologia não são demarcações contingentes dos domínios, nem terminologias, etc., mas fundamentos de princípio, noção que influenciara bastante a tese doutoral de Heidegger.

A fenomenologia aparece aqui como uma crítica à base dos princípios de experiência. Husserl, esclarecendo melhor esta distinção, diz:

A psicologia é uma ciência empírica. Dois aspectos estão contidos na significação usual da palavra experiência: 1 . Ela é uma ciência de fatos no sentido de David Hume. 2. Ela é uma ciência de realidades. Os fenômenos de que ela trata enquanto fenomenologia psicológica são eventos reais, que, como tais se possuem existência efetiva insere-se junto com os sujeitos reais a que pertencem na ominitudo realitatis que o mundo espaço temporal.

Em comparação a isso, a fenomenologia pura ou transcendental não será fundamentada como ciência de fatos, mas como ciência de essências (como ciência eidética); como uma ciência que pretende estabelecer unicamente conhecimentos de essências e de modo algum de fatos. A redução aqui em questão que leva o fenômeno psicológico à essência pura ou, no pensamento judicante, da universalidade fática (empírica) à universalidade de essência é a redução eidética. 
Husserl e a metafísica da subjetividade: uma crítica heideggeriana a partir da noção de superação
Dr. Gustavo

Augusto da Silva

Ferreira [UFC]

Em segundo lugar, os fenômenos da fenomenologia transcendental serão caracterizados como irreais. (...) Nossa fenomenologia não deve ser uma doutrina das essências de fenômenos reais, mas de fenômenos transcendentais reduzidos. (HUSSERL, 2006, Pp. 27-28)

Podemos assim observar que dois pontos entram em choque no que tange aos conceitos preliminares e que se expandem no transcurso do nosso objetivo: fato e essência, real e não-real ou real e ideal. Conceitos que se demonstram como essenciais para a precedente análise da questão fenomenológica, principalmente por contarem com o aparato teórico e formal intelectual da tradição da metafísica da subjetividade. A realidade, tanto a realidade da coisa tomada isoladamente, como a realidade do mundo inteiro, é por essência desprovida de independência. Ela não é em si algo absoluto (isto é, na medida em que é considerada enquanto algo correlato à consciência e não em si mesmo. Pois, eliminada, pura e simplesmente, a pressuposição de algo em si mesmo, e neste sentido, absoluto, embora inacessível, não estaríamos mais numa postura transcendental) e que secundariamente se submete a um outro, mas, no sentido absoluto, não é nada, não tem essência absoluta, tem a essencialidade de algo que é por princípio algo apenas intencional, um conscientizado, um representado, um aparecimento na forma de consciência-de.

Em vez, então, de viver ingenuamente na experiência e de investigar teoricamente aquilo que se experimenta, ou seja, natureza transcendente, efetua-se a redução fenomenológica. Em suma, na orientação fenomenológica, impede-se, em generalidade de princípio, a efetuação de todas essas teses cognitivas, isto é, nós colocamos, como diz Husserl, entre parênteses as teses efetuadas na postura natural, e não compartilhamos dessas teses para fazer novas investigações. Em vez de nelas viver, de as efetuar, efetuamos atos de reflexão a elas direcionados. Aqui entram em jogo, através do estudo das condições de possibilidade do aparecer de qualquer objeto, o que torna possível a sua constituição. Em Husserl: constituinte (sujeito) e constituído (objeto).

A existência de uma natureza não pode condicionar a existência da consciência, uma vez que ela mesma se mostra como correlato da consciência; ela somente é enquanto se constitui em nexos regrados de consciência. Isso quer dizer que a consciência independe da natureza. Logo, por partirem da pressuposição do domínio óptico, empírico e psicológico da questão do conhecimento e da consciência, e por considerarem a natureza no caminho totalmente inverso ao caminho da própria consciência, a mecânica, a física, a química em seus 
inúmeros elementos, enfim, todas as demais ciências se resumem em uma única ciência natural, do ponto de vista de sua classe, método estruturas - são saberes objetivistas, por ignorarem a mediação da consciência.

O eidos, a essência pura, é o que se busca na fenomenologia pura, ou, se preferir, fenomenologia transcendental. Em contrapartida, o conhecimento natural começa na essência e continua na mesma até seu encerramento, ou seja, o retorno à esfera de mediação não se faz. O ser individual, qualquer que seja sua espécie, é ele contingente. Nesta perspectiva, as ciências empíricas como ciências de fatos apoderam-se da proporção experimental na esfera do ser.

A questão é que admitimos, com demasiada dificuldade, que por essência própria todo fato poderia ser, por assim dizer, diferente. Com isso já exprimimos que faz parte do sentido de todo contingente ter justamente uma essência e, por conseguinte, um eidos a ser apreendido em sua pureza, e ele se encontra sob verdades de essência de diferentes níveis de generalidade, segundo a perspectiva de Husserl.

Porém, enquanto contingências e percepções, é nos vividos que se encontra o nosso principal objeto, não obstante, também o do psicologismo. Devemos, na perspectiva husserliana, antes de qualquer coisa, observar que não se está falando aqui de um evento psicológico qualquer - chamado vivido - e uma existência real — chamada objeto real — ou de um vínculo psicológico entre um e outro que se daria na efetividade objetiva. Estamos aqui, ao contrário, nos referindo a Husserl, falando de vividos por essência puros. ${ }^{15}$ Os vividos são considerados sob um ponto de vista determinado e altamente importante quando os reconhecemos como intencionais e quando, a seu respeito, enunciamos que são consciência de algo.

O naturalismo, tendo como pressuposto a sua base empírica totalmente voltada para a efetividade, toma como pressuposto de realidade tudo aquilo que pode ser sentido no sentido de objetividade e da experiência propriamente dita como a real essência, ou melhor, toma o real em si. O pressuposto do real em si demonstra uma gigantesca ingenuidade filosófica (ou ingenuidade intelectual no sentido de provocar em si mesmo quase de maneira arbitrária o equívoco). Porém, tudo aquilo que não se pode provar, experimentar ou considerar como efetivo, o cientista natural toma como imaginação, fictício, até mesmo i-real. Tal é a estrutura do pensamento naturalista, da postura natural, que a mera proposição fenomenológica, que põe fora de circuito toda à realidade em questão, considera ou acusa como improvável.

15 Por vividos no sentido mais amplo, Husserl entende não apenas os vividos intencionais, as cogitationes (como ele chama nas Investigações lógicas) atuais e potenciais tomadas em sua plena concreção, mas tudo o que for encontrado em momentos reais desse fluxo e em suas partes concretas. 
Husserl e a metafísica da subjetividade: uma crítica heideggeriana a partir da noção de superação

Aqui, põe-se o mundo e toda sua "efetividade" entre parênteses, em suspensão, a realização da redução fenomenológica. ${ }^{16} \mathrm{~A}$ teoria psicológica, atitude naturalista comum para com o real, afirma com audácia que o que existe de fato só pode ser eventos psíquicos reais da abstração, fervorosamente "teorias da abstração", e a psicologia, orgulhosa de sua empiria, é assim enriquecida por si mesma. Aqui, como também em todas as esferas "intencionais" (que constituem o tema principal da psicologia e que não obstante aproxima-a de nós na medida em que também nos apropriamos da intencionalidade como ato doador indispensável inerente à fenomenologia), de fenômenos inventados, de análises psicológicas que não são, segundo Husserl, análises coisa alguma, é onde se sustenta o psicologismo.

Em nossa leitura, compreendemos que ideias ou essências são conceitos, e conceitos são construtos psíquicos, produtos de abstração, e como tais, certamente desempenham um grande e considerável papel em nosso pensamento.

Existem, como temos dissertado, ciências de pura essência e ciências de fatos: a fenomenologia não é a primeira a trabalhar no âmbito das essências, porém é a mais pretensiosa. Acerca de tais ciências, cito o próprio Husserl:

\footnotetext{
Há puras ciências de essência, como a lógica pura, a matemática pura, a pura doutrina do tempo, do espaço, do movimento etc. todas ela são, em todos os passos do pensamento, inteiramente puras de quaisquer posições de fatos; ou, o que é equivalente, nelas nenhuma experiência como experiência, isto é, como efetividade, como consciência que apreende ou põe existência, pode assumir a função de fundação. (HUSSERL, 2006, P. 42)
}

Não é preciso uma experiência efetiva ou um ato de estrutura empírica para a realização de tais ciências: as ciências de essências. O matemático ou o geômetra constroem a sua fundamentação racional sem nenhuma base empírica concreta no âmbito da efetividade material. E Husserl continua, afirmando a contrariedade do cientista natural com relação ao procedimento das ciências de essências:

16 Em Husserl, é importante salientar, há três níveis de redução: a fenomenológica (principal), promove o afastamento de todas as "evidências" para que a consciência possa ser descrita em "si mesma", o que constitui o que Husserl chama de epoché; a eidética, que diz respeito a captação da essência ou do universal, do invariante; e a transcendental, a qual se refere a estrutura noético-noemática, a qual só alcançada em sua vitalidade quando ao aspecto estrutural se acrescenta o aspecto dinâmico teleológico, que se alcança através das duas reduções anteriores. Não nos adentraremos nisso, o foco aqui não é propriamente a declinação do pensamento de Husserl enquanto tal em suas principais questões, o mesmo aqui surge como propedêutico, em seus aspectos básicos, à continuação, do ponto de vista da crítica fenomenológica, à perspectiva heideggeriana. 
Husserl e a metafísica da subjetividade: uma crítica heideggeriana a partir da noção de superação

$\mathrm{O}$ cientista natural procede de maneira inteiramente outra. Ele observa e experimenta, isto é, ele constata a existência de acordo com a experiência, experimentar é para ele ato fundante, jamais substituível por um imaginar. (...) Não é a experiência, mas a apreensão intuitiva da essência ato fundante último.

(HUSSERL, 2006, P. 42)

A especificidade da argumentação husserliana abre margem para um imenso leque de exemplificações abstratas que nós mesmos poderíamos fazer para a comprovação ou validação de tais teses. Nossa percepção sempre se volta para algo, mesmo que esse algo só se mostre de uma forma ímpar e quase inapreensível em sua existência efetiva, ou muito pouco apreensível a ponto de se realizarem interpretações errôneas da consciência daquele algo, o objeto. Ainda assim realizamos abstrações que formulam juízos (no sentido kantiano) abstratos acerca do que nos é dado como efetivo, em suma, independentemente da efetividade do objeto, o seu construto é dado para nós em primeira instância no campo da consciência, e não da experiência que julga o objeto como efetivo. Posteriormente, mesmo depois da experiência e da constatação do objeto efetivo, temos a leve percepção e a observação de que em outros modos de se apresentar, o objeto, tal como é, se mostra para nós de outras formas e em outros momentos. E logo construímos novas abstrações sobre o mesmo objeto efetivo mesmo depois da experiência e da constatação de sua objetividade.

Lembremos o exemplo da árvore, dado pelo próprio Husserl no $§ 89$ de Ideias para uma fenomenologia pura e para uma filosofia fenomenológica: a árvore se esvai em seus elementos químicos, mas a ideia e a lembrança, a essência e a percepção, quer dizer, a árvore como percebida, o sentido desta percepção - em forma de lembrança - continuam. Que algo efetivo no espaço corresponda a tais verdades não é um mero fato, mas, como particularização de leis de essência, uma necessidade eidética. Fato aí é apenas o mero efetivo, ao qual as leis se aplicam.

A visão das essências é uma intuição, isto é, um ato de conhecimento direto, sem intermediários, que nos põe em presença, num face a face ao objeto "em pessoa". Ele chamará, a este ver que constitui seus objetos, de intuição doadora, de "intencionalidade". Conhecer é ver, colocar-se à distância dos objetos, dirigir-se a eles (in-tensio), visá-los progressivamente.

O caminho seguido por Husserl, de modo algum o opôs à tradição em que Heidegger o insere. Isso graças ao uso dos mesmos operadores e a mesma visão dicotômica de mundo: sujeito-objeto, por via de uma interpretação da consciência e do império da mesma, primazia da representação, ou, no caso específico 
de Husserl, da intencionalidade. A notável crítica de Husserl ao que o mesmo chamara de naturalismo, apesar de ter fortemente influenciado Heidegger em seus escritos de juventude, incluindo sua tese doutoral, funcionara, num segundo momento, como mote da crítica heideggeriana ao seu honorável mestre. O usufruto da noção husserliana de fenomenologia, por parte de Heidegger, logo expõe a necessidade de superação do seu próprio mestre.

\title{
Desconstrução do auge da metafísica da subjetividade
}

Carlos Alberto Ribeiro de Moura, no prefácio à segunda edição (brasileira) de Ideias para uma fenomenologia pura e para uma filosofia fenomenológica, sublinhando o que Husserl diz no $§ 153$ desta mesma obra, afirma que:

\begin{abstract}
A filosofia, para Husserl, é essencialmente uma investigação crítica do conhecimento, e por isso mesmo ela não falará do mundo, ela não será um método de compreensão de realidades, (...) para Husserl, não haverá fenomenologia do ser, mas apenas uma fenomenologia da razão (...). (MOURA, 2006, P. 18).
\end{abstract}

Se isso estiver certo, então teremos que concordar com o que Ernildo Stein exorta sobre a noção de mundo entre Husserl e Heidegger: a noção de mundo seria exatamente o ponto de separação entre a fenomenologia transcendental (Husserl) e a fenomenologia hermenêutica (Heidegger), e, portando, o ponto nodal também do rompimento de Heidegger com a tradição, a qual o mesmo tanto respeita, mas com demasiado pesar se vê na obrigatoriedade de superar. Para Stein, se apoiando em trechos significativos da carta de Heidegger a Husserl, a qual citamos anteriormente, em especial, se apegando à parte em que Heidegger se refere ao Dasein, afirmando que a questão do modo de ser do constituinte é incontornável, diz Stein que:

Os elementos unilaterais do corpo e da psicologia pura nos quais Husserl insistia muito só são possíveis sobre a base de uma integralidade concreta do homem, tal como ele é determinado primeiramente em seu modo de ser. Quer dizer: corpo e espírito, o elemento somático e o elemento psíquico, pressupõem esse modo de ser do Dasein, onde se constitui aquilo que se chama mundo. (...) 
Husserl e a metafísica da subjetividade: uma crítica heideggeriana a partir da noção de superação
Dr. Gustavo

Augusto da Silva

Ferreira [UFC]

O "ponto fraco" de Husserl era exatamente essa questão: se eu reduzo tudo aos polos noético e noemático do Eu transcendental, para ver se há uma constituição como conhecimento sujeito-objeto, eu necessariamente faço isso em uma dimensão, em algum lugar. Esse lugar é o ser humano concreto o ser humano com seu enraizamento num mundo vivido. Como reduzir aquilo que sustenta o Eu transcendental, e também este, à dimensão transcendental do polo sujeito-objeto, nóesis noésios? Como dar àquilo que sustenta a redução transcendental uma redução transcendental? Impunha-se uma espécie de objeção de circularidade transcendental inaceitável. (STEIN, 2010, Pp. 289-290).

Esta perspectiva abre as portas para a lacuna da historicidade, a qual, em relação à verdade, a tradição não irá pensar. $\mathrm{O}$ sujeito, como inquietantemente declinará Foucault em seus escritos, sob a assumida influência de Heidegger, é fundamentalmente histórico. $\mathrm{O}$ ente que passa a constituir o lugar de verdade desde o primado da modernidade, esta inserido em um lugar de verdade. $\mathrm{O}$ mote da fenomenologia hermenêutica, longe de um procedimento objetivista ou especulativo, tendo como basilar em sua estrutura o conceito de compreensão, é o pilar da destruição e proposta de retorno, fundamentação da crítica à metafísica da subjetividade. Mas o retorno aqui, o passo de volta, o viés fundamentalmente hermenêutico, não exclui, por assim dizer, o transcendental, pelo menos não o transcendental tal como Heidegger compreende esta noção. Heidegger não abre mão disso, mas o transcendental heideggeriano, tal como o mesmo entende tal noção, é interpretado como tradução do metá grego: trans = metá, em sua intenção de traduzibilidade. Se assim o é, a dimensão do que torna possível o ir além, o transcendental, tem, na qualidade de passo de volta, de fator hermenêutico, a intenção de trazer:

(...) essa originalidade e essa radicalidade para um espaço anterior à subjetividade e de criticar a ideia de subjetividade como fundamento último, dizendo que ele sempre mergulha no fático, portanto, tem condições históricas, é retirar da subjetividade a sua condição de verdadeira transcendentalidade. (STEIN, 1993, P. 120).

O cogito ergo sum chegou, partindo do século XVII, ao século XX, sem impedimentos, com várias modificações e reconfigurações, mas mantendo a mesma 
significação, o lugar de esquecimento do ser, o ontoteológico em sua última configuração central, como metafísica da subjetividade. Mas como isso foi possível, como foi possível até mesmo em Descartes, primeiro momento, e em Husserl, último momento, esta egocidade exacerbada perdurar?, questiona Heidegger.

\footnotetext{
Mas como Descartes, um homem tão sábio e razoável, chega a uma teoria tão estranha de que o homem existe apenas para si, sem relação com as coisas? Husserl, meu venerado mestre, acompanhou amplamente esta teoria, mas já intuiu algo além dela. Senão suas Meditações cartesianas não seriam um livro fundamental. (HEIDEGGER, 2009, P. 147).
}

Há aqui três perguntas que se constituem a partir desta fala de Heidegger: a primeira seria: como se perdurou isso - a metafísica da subjetividade? A segunda: que Husserl, apesar de inserido nessa teoria, intuiu para além dela? E, por fim: por que as Meditações cartesianas é uma obra fundamental? A resposta à primeira pergunta foi o que narramos, de maneira breve no itinerário teórico do presente escrito e é pressuposto na totalidade da filosofia heideggeriana, ou seja, o esquecimento do ser em favor do ente: a caracterização - ontoteológica do sujeito - de um ente em detrimento do ser, a qual cumpriu seu curso histórico de determinação quase obrigatória a partir da consideração de sua progressão nesse engano fundamental, o esquecimento do ser. A segunda pergunta se responde observando o que dissertamos sobre Husserl anteriormente, ou seja, a noção de intencionalidade, herdada da leitura tomista da intentio de Brentano, e aperfeiçoada na fenomenologia transcendental. E, por fim, a terceira pergunta se responde com a simples compreensão de que é justamente nas Meditações cartesianas que surge essa forma absoluta de transcendental, o último modus da metafísica da subjetividade, a fenomenologia, ou, se preferir, a última característica desse apelo de relação com o ser, que temos chamado de transcendental.

O transcendental, a partir da concepção de intencionalidade, parece vir, nessa última roupagem, para assegurar a fenomenologia enquanto esta assegura o sujeito. $\mathrm{O}$ apelo ao transcendental é normal e necessário, todavia, na equivocidade da metafísica da subjetividade, este apelo, somente se mantém no apontamento correto em sua intenção, não em seu modo de operar, não em seu modo de proceder. O transcendental aqui, herdado de Kant, é fator constituinte da filosofia de Husserl, e, portanto, de uma certa metafísica da subjetividade, ou, se preferir, da tradição da metafísica da subjetividade. O caráter transcendental 
que emerge em Ser e tempo, tal como nos lembra Stein ${ }^{17}$, tem uma dimensão hermenêutica fundamental, um espaço anterior à subjetividade, e não uma subjetividade fundamentalmente fundante da realidade, como espaço último da realidade, ao contrário do que parece ter sugerido Ludwig Binswagner ao fundar a Daseinanalise.$^{18}$ Heidegger afirma que:

Em suas Investigações lógicas, publicadas em 1900/01, Husserl fala de atos que conferem significados. De acordo com ele a constituição de um objeto da consciência realiza-se de tal modo que, primeiramente, existem os dados hiléticos, puras sensações, que depois recebem significado noematicamente, isto é, pelo pensamento. Em outras palavras, confere-se um significado ao estímulo através de um ato psíquico. Entretanto, tudo isso é pura construção. (HEIDEGGER, 2009, P. 248).

O homem não é uma pura sequência de processos em relação à realidade, constituindo-a; para Heidegger isso "(...) seria desumano". (HEIDEGGER, 2009, P. 249). Entra aqui, sobretudo, a questão da compreensão. Por mais que quiséssemos contar com essa relação sujeito-objeto como primado da realidade, o questionamento de como essa relação é possível seria inevitável, do pondo de vista da constituição do constituinte. O homem já opera com uma compreensão do ser, esta estando previamente estabelecida, como Heidegger sublinha com maestria em Ser e tempo.

Ao ser da presença ${ }^{19}$ pertence uma compreensão de ser. Compreensão tem o seu ser no compreender. Se convém essencialmente à presença o modo de ser-no-mundo, é que compreender ser-no-mundo pertence ao teor essencial de sua compreensão de ser. A abertura prévia da perspectiva, em

17 Cf.: STEIN, Ernildo. Seminário sobre a verdade. Lições preliminares sobre o $\S 44$ de Sein und Zeit. Editora Vozes. Petrópolis. 1993. P. 120 e p. 123.

18 Heidegger: "Se Ludwig Binswagner (...) escreve que Ser e tempo é uma sequência extremamente coerente dos ensinamentos de Kant e Husserl, isso é totalmente errado, já que a questão que se coloca em Ser e tempo não é colocada em Husserl nem em Kant, aliás, nunca foi colocada antes na filosofia." HEIDEGGER, Martin. Seminários de Zollikon. Editora Vozes e Editora Universitária São Francisco. Ed. 2 ${ }^{\mathrm{a}}$. Trad. De Gabriella Arnhold e Maria Fátima de Almeida Prado. São Paulo. 2009. P. 155.

$19 \mathrm{Na}$ tradução de Ser e tempo que nos utilizamos para a produção do presente escrito, se traduziu Dasein por presença. 
que acontece a liberação dos entes intramundanos que vêm ao encontro, nada mais é do que o compreender de mundo com que a presença, enquanto ente, está sempre em relação. (HEIDEGGER, 2006, Pp. 136-137)

Compreensão não é ir às coisas elas mesmas nem trazê-las para o intelecto e assim desvendá-las, mas é, isto sim, a caracterização de uma limitação essencial do ser-no-mundo, onde compreender não é conhecer — pelo menos não conhecer num sentido epistemológico, de uma teoria do conhecimento etc. mas a pressuposição da possibilidade de se relacionar, portanto, não um lugar de verdade, mas de relação, relação com o ser.

Stein afirma que:

O projeto de Ser e tempo, mediante a ideia da compreensão do ser é, um projeto que já sempre radica numa história do ser. Há uma história da filosofia que precede toda discussão da questão da verdade. (...)

Isto é o lado do ser, mas fundamentalmente, também, o acesso à história do ser. Essa história do ser que nos determina com o nosso projeto de compreensão do ser e que nos limita. (STEIN, 2006, Pp. 28-29).

A admissão de um Constituinte fundamental como determinante de um constituído, levar-nos-ia, mais uma vez, a uma teoria da totalidade ou de um certo absoluto, mas agora, não como o absoluto em Hegel, mas o de Descartes em sua fundamentação absoluta do conhecimento. Mas um absoluto ainda é um absoluto, ainda resguarda a dimensão de totalidade abarcada, e o que interpreta determinando (Descartes) ou constitui sendo o determinante (Husserl), de forma omniabrangente, cai naturalmente naquilo que Stein chama de "paralaxe cognitiva", onde nós deveríamos nos situar do lado de fora da realidade para determiná-la, onde, para determinarmos o todo, teríamos que nos colocar fora do mesmo, problema que segundo Stein, em sua leitura heideggeriana, se inicia em Aristóteles e, ao que parece, tal paradoxo constitui as variações históricas do esquecimento do ser desde que se assumiu a história do Ocidente como história de tal esquecimento. ${ }^{20}$

20 C.f.: STEIN, Ernildo. Às voltas da metafisica com a fenomenologia. Editora Unijuí, 2014. Rio Grande do Sul - RS. P. 35. 
Husserl e a metafísica da subjetividade: uma crítica heideggeriana a partir da noção de superação

A fenomenologia husserliana acompanha e sustenta tal paradoxo, fator de relevo para a metafísica da subjetividade. A fenomenologia em Heidegger, enquanto contando com o princípio transcendental, como citamos há pouco, deve ser mantida sem esse viés de totalidade, portanto sem sujeito, mas completamente necessária a qualquer análise filosófica prévia (de um sujeito ou de qualquer outra configuração onto-teo-lógica), como Heidegger afirmava antes mesmo de escrever Ser e tempo ${ }^{21}$. Heidegger afirmara que a filosofia é uma ontologia fenomenológica ${ }^{22}$. Isso deixa claro que o trato com a questão do ser enquanto o mostrar-se na qualidade de fenômeno é, de maneira objetal, quer dizer, enquanto modo de proceder da filosofia com seu objeto, o ser, o cerne da filosofia. A fenomenologia (não se concentrando na correlação sujeito-objeto), não ocuparia assim o lugar de descrição da relação sujeito-objeto, pois mundo, um dos conceitos fundamentais da metafísica, já ocuparia lugar privilegiado para além da dicotomia sujeito-objeto, já que, em nosso modo de ser, já operamos com a dimensão da compreensão, em relação ao ser, de maneira previamente estabelecida, não como sujeitos, mas como ser-com (mit-sein), onde "A questão do ser não é senão a radicalização de uma tendência ontológica essencial, própria da presença, a saber, da compreensão pré-ontológica de ser." (HEIDEGGER, 2006, P. 51).

Segundo Stein, Em Husserl, a compreensão do ser se daria na redução trans-
cendental, e não na compreensão de mim como indivíduo finito
e histórico. É isso que vai produzir as duas dimensões radicais
de separação: a fenomenologia transcendental é a radicaliza-
ção impossível da psicologia pura. A fenomenologia herme-
nêutica é a radicalização da história e, portanto, a introdução
da historicidade com todos os elementos do Dasein que são
descritos na analítica existencial. (STEIN, 2010, P. 294).

21 "Na década de 1920, Heidegger sustentava que toda filosofia deva ser fenomenologia: considerar a fenomenologia como mera "propedêutica" a algum outro tipo de filosofia é como considerar a física como uma propedêutica à astrologia ou a química como um prelúdio à alquimia. Ele dá uma explicação dos dois constituintes da fenomenologia". INWOOD, Michael. Dicionário Heidegger. Jorge Zahar Editor, 2002, Rio de Janeiro - RJ. P. 65. E, também, Cf.: HEIDEGGER, Martin. Ser e tempo. Editora Vozes e Editora Universitária São Francisco. Ed. 5a. Trad. De Márcia de Sá Schuback. Petrópolis - RJ. 2006. P. 66-68, e p. 70.

22 Cf:: HEIDEGGER, Martin. Ser e tempo. Editora Vozes e Editora Universitária São Francisco. Ed. $5^{\text {a }}$ Trad. De Márcia de Sá Schuback. Petrópolis - RJ. 2006. P. 78. 
Husserl e a metafísica da subjetividade: uma crítica heideggeriana a partir da noção de superação

\section{Considerações finais}

A crítica heideggeriana da metafísica da subjetividade, em especial quando esta se dirige diretamente a Husserl, fora tão significativa que fizera com que o próprio Husserl, na qualidade de grande pensador que o mesmo fora, revisse suas ideias e as condições de possibilidade da fenomenologia transcendental, inserindo em seus pensamentos, de maneira veemente e inovadora, a noção de mundo, mas não no sentido crítico heideggeriano, mas a noção de mundo da vida, ou mundo vivido (Lebenswelt), noção que já surgira em escritos anteriores, mas que será mais profundamente analisada em A crise das ciências europeias e a fenomenologia. ${ }^{23}$ Todavia, tal reflexão autocrítica, ao trazer a noção de mundo vivido, juntamente com a noção de intersubjetividade — esta última sendo bem problemática e polêmica ao pensamento de Husserl ${ }^{24}$ —, ainda se contou normativamente com o conceito de consciência, concepção de apreensão do real por via de um Constituinte, ainda um sujeito fundamental como fator determinante do objeto, mantendo a separação entre hermenêutica e fenomenologia, ou fenomenologia hermenêutica e fenomenologia transcendental.

Segundo a concepção de Stein,

Superação, destruição e dissolução não significam apenas não mais aceitar a subjetividade como lugar originário e universal da fundamentação do conhecimento. Para fazer isto, acrescenta-se à tradição metafísica uma hipótese mais radical: a questão do ser-no-mundo, a analítica do Dasein, a hipótese de que já estamos faticamente comprometidos com a historicidade da verdade. (STEIN, 2006, P. 138, grifo nosso)

Superação aqui, no que é relativo ao sujeito, não significa demolição e aban-

23 Segundo Stein, "Husserl percebeu as consequências da crítica e, por isso, escreveu $A$ Crise das Ciências Europeias (Husserl, 1976) e retomou a questão do mundo vivido, que tentou reduzir também ao nível transcendental da consciência. E essa redução exigiria uma operação constante de reduzir todas as dimensões da cultura e da história à dimensão transcendental, tanto na direção do passado como na direção do futuro." STEIN, Ernildo. Mundo e Subjetividade: o núcleo da diferença entre Husserl e Heidegger. Presente em: As voltas com a questão do sujeito, posições e perspectivas. Org. César Augusto Battisti. Editora UNIOESTE e UNIJUí. Paraná - RS. 2010. P. 290.

24 Acerca de tal problemática e da relação subjetividade-intersubjetividade e mundo vivido, remeto o leitor a: MARSCIANI, Francesco. Subjetividade e intersubjetividade entre semiótica e fenomenologia. Presente em Galaxia. № 28, p. 10-19, dezembro de 2014. E, também, CADENA, Nathalie Barbosa de, A importância da intersubjetividade para Husserl. Presente em Cadernos da EMARF, v.8, n⿳亠口冋 1 , setembro de 2015. Pp. 47-63. 
dono total, mas dissolução. Quando se apresentam os pressupostos da insustentabilidade de algo em sua equivocidade basilar, se torna possível que a coisa, ela mesma, se dilua, não havendo mais condições de possibilidade de sua sustentação, portanto, o princípio e decreto de sua dissolução. Heidegger não substitui ou destrói o sujeito, ele somente o dilui, não havendo a necessidade de um substituto fundamental para o mesmo. A crítica heideggeriana à metafísica da subjetividade e, consequentemente a Husserl, se constitui como dissolução do sujeito; a crítica heideggeriana da metafísica da subjetividade, ao apontar suas fragilidades a partir da análise destas como momentos de continuação radical do esquecimento do ser tendo seu auge na fenomenologia husserliana, constitui o processo de realização da crítica da metafísica da subjetividade A crítica heideggeriana à história do pensamento ocidental e proposta de superação da metafísica, quando direcionada para a metafísica da subjetividade, constitui um longo processo de dissolução, em sua estrutura arquitetônica e narrativa crítica, a qual, inevitável e respeitosamente, deságua em Husserl.

Recebido em: 02.08.2018| Aprovado em: 25.09.2018 Referência Bibliográfica

GADAMER, H.G. - Geleitwort. In: Biemel, W. e Hermann, F-W (editores) - Kunst und Technik - Frankfurt a. M., 1989.

HEIDEGGER, Martin. Seminários de Zollikon. Ed. $2^{\text {a }}$. São Paulo. Editora Vozes e Editora Universitária São Francisco.. Trad. De Gabriella Arnhold e Maria Fátima de Almeida Prado. 2009.

.Kant und das Problem der Metaphysik. Frankfurt am Main: Vittorio Klostermann, 1991.

. Ser e tempo. Ed. 5a. Petrópolis - RJ. Editora Vozes e Editora Universitária São Francisco. Trad. De Márcia de Sá Schuback, 2006.

HUSSERL, E. Ideias para uma fenomenologia pura $e$ para uma filosofia fenomenológica. Ed 2a. Aparecida SP. Editora Ideias e Letras. Trad. de Márcio Suzuki. 2006.
INWOOD, Michael. Dicionário Heidegger. Rio de Janeiro - RJ. Jorge Zahar Editor. 2002.

MOURA, Carlos Alberto R.. Prefácio à segunda edição de Ideias para uma fenomenologia pura e para uma filosofia fenomenológica. Presente em: HUSSERL. E. Ideias para uma fenomenologia pura e para uma filosofia fenomenológica. Ed 2a . Aparecida - SP. Editora Ideias e Letras. Trad. de Márcio Suzuki. 2006.

STEIN, Ernildo. Lições preliminares sobre o $\$ 44$ de Sein und Zeit. Ijuí, RS. Editora UNIJUÍ. 2006.

Mundo e Subjetividade: o núcleo da diferença entre Husserl e Heidegger. Presente em: Às voltas com a questão do sujeito, posições e perspectivas. Org. César Augusto Battisti. Paraná - RS. Editora UNIOESTE e UNIJUÍ. 2010. 
Seminário sobre a verdade. Lições preliminares sobre o $\$ 44$ de Sein und Zeit. Petrópolis. Editora Vozes. 1993.

Às voltas com a metafísica e a fenomenologia. Ijuí, Rio Grande do Sul - RS. Editora Unijuí, 2014. Destruição da metafísica ou crise da metafísica e crise da estética (simetria e reversibilidade). Presente em: Revista do Programa de Pós Graduação em Letras da UFSM. No 54. Junho de 2017.

TORRES, Jesús Vásquez. Subjetividade transcendental e transcendentalidade do Dasein: aproximações entre Husserl e Heidegger. Presente em: Revista Perspectiva Filosófica. V. VII, número 14. Jul/dez./2000. P. 72. 